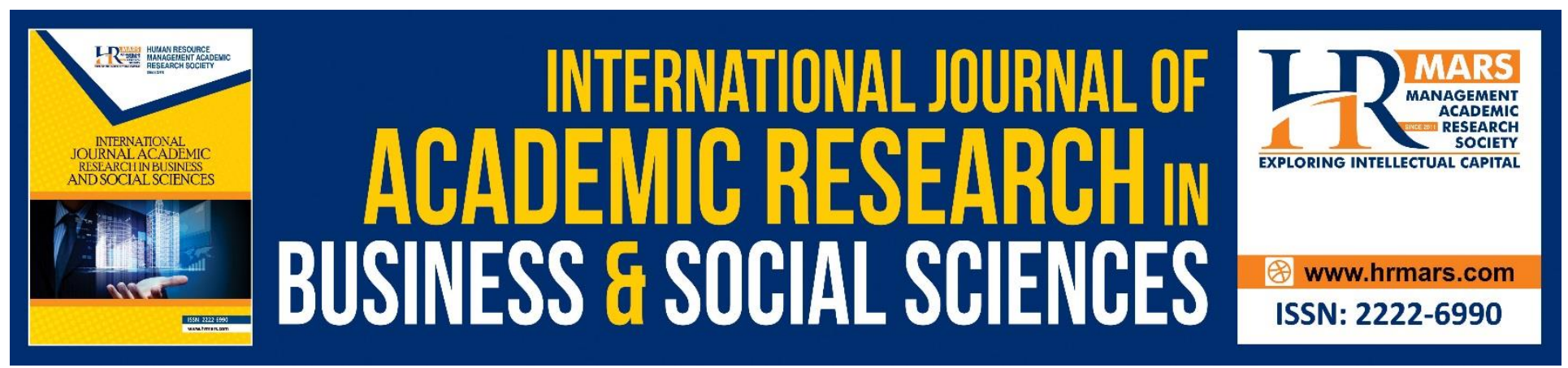

\title{
Toward the Development of a Unique, Mobile, Hanging, Tennis Practice Backboard: A Case Study
}

Hazuan Hizan, Thariq Khan Azizuddin Khan, Abd Rahim Mohd Shariff, Nordiana Ahmad Kharman Shah and Brad Muise

To Link this Article: http://dx.doi.org/10.6007/IJARBSS/v8-i12/5587 DOI: $10.6007 /$ IJARBSS/v8-i12/5587

Received: 13 Nov 2018, Revised: 16 Dec 2018, Accepted: 21 Dec 2018

Published Online: 29 Dec 2018

In-Text Citation: (Hizan, Khan, Shariff, Shah, \& Muise, 2018)

To Cite this Article: Hizan, H., Khan, T. K. A., Shariff, A. R. M., Shah, N. A. K., \& Muise, B. (2018). Toward the Development of a Unique, Mobile, Hanging, Tennis Practice Backboard: A Case Study. International Journal of Academic Research in Business and Social Sciences, 8(12), 2428-2438.

Copyright: @ 2018 The Author(s)

Published by Human Resource Management Academic Research Society (www.hrmars.com)

This article is published under the Creative Commons Attribution (CC BY 4.0) license. Anyone may reproduce, distribute, translate and create derivative works of this article (for both commercial and non-commercial purposes), subject to full attribution to the original publication and authors. The full terms of this license may be seen

at: http://creativecommons.org/licences/by/4.0/legalcode

\section{Vol. 8, No. 12, 2018, Pg. $2428-2438$}

Full Terms \& Conditions of access and use can be found at http://hrmars.com/index.php/pages/detail/publication-ethics 


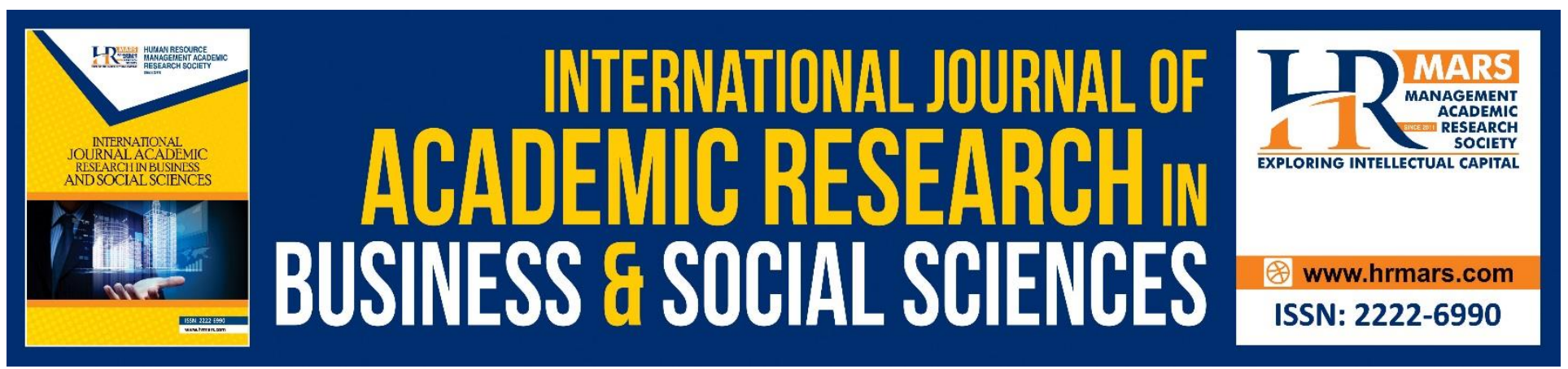

\title{
Toward the Development of a Unique, Mobile, Hanging, Tennis Practice Backboard: A Case Study
}

\author{
Hazuan Hizan ${ }^{1}$, Thariq Khan Azizuddin Khan ${ }^{1}$, Abd Rahim Mohd \\ Shariff' ${ }^{1}$, Nordiana Ahmad Kharman Shah ${ }^{2}$ and Brad Muise ${ }^{3}$ \\ ${ }^{1}$ Faculty of Sport Science and Coaching, Sultan Idris Education University, Perak, Malaysia \\ ${ }^{2}$ Faculty of Computer Science \& Information Technology, University of Malaya, Kuala \\ Lumpur, Malaysia \\ ${ }^{3}$ Engineering Consultant, 726 Whitesprings Drive, Geneva, New York, 14456, USA \\ Email: hazuan@fsskj.upsi.edu.my
}

\begin{abstract}
A new and unique mobile, hanging, tennis backboard prototype (HTB) has been developed to aid players in practicing tennis independent of other players. An examination of existing return mechanics from stand alone backboards, such as the popular Tennis Partner ${ }^{\mathrm{TM}}$ and Miracle Tennis ${ }^{\mathrm{TM}}$, were conducted and it was determined that slow, near shot returns and quick, far shot returns were required. In addition, it was determined that to utilize space in tennis court more efficiently, the device must be capable of being installed on chain link fences typically found in such courts. While chain link fences are strong enough to withstand rebounding forces, their slightly flexible, interwoven characteristics make them a challenging substrate to anchor a backboard. This case study examined the engineering steps taken to overcome these challenges and allow the prototype to perform returns reliably.
\end{abstract}

Keywords: Sport Engineering, Self Training Tennis Tool, Tennis Training Equipment

\section{Introduction}

Various forms of tennis backboards are currently being used as independent training tools for recreational, as well as professional tennis players around the world (Annapragada 2016; McTavish 2010; Chang and Moore 2005; Hutchins 2015). Many backboards can be easily purchased online from sites such as Amazon.com ${ }^{\mathrm{TM}}$ and Alibaba.com ${ }^{\mathrm{TM}}$. These sites often provide product images, specifications and a customer feedback area that can, in some instances, include insights that relates to their reliability. An overview of commonly available backboards is presented along with their features, specifications and related customer feedback. The Tennis Partner ${ }^{\mathrm{TM}}$ is a stand-alone, practice backboard that includes a tubular steel frame with curved top rails and a center angle adjustment. While the Tennis Partner ${ }^{\mathrm{TM}}$ is sturdy and provides several return options, it tends to be 
heavy and setup can be somewhat complicated. The Miracle Tennis ${ }^{\mathrm{TM}}$ is an adjustable, stand-alone backboard with center angle adjustments. While it is very lightweight, some of the thin-walled components may be prone to reliability issues after prolonged use. The Great Base Backboard ${ }^{\mathrm{TM}}$ (which also appears to be rebranded as the Perfect Pitch Rebounder ${ }^{\mathrm{TM}}$, and the Tennis Smith ${ }^{\mathrm{TM}}$ ) is a stand-alone backboard with a polyvinyl chloride (PVC) plastic frame that does not adjust. Customers have reported that while the backboard is somewhat expensive and retention springs wear out over time, they were very satisfied with its assembly and ease of use. The XK Sports Tennis Rebounder ${ }^{\mathrm{TM}}$ is a non-adjustable, stand-alone backboard with tubular metal frame. Customers reported items missing in shipment and assembly instructions were poor. An examination of the product video reveals the frame to be lightweight but it may suffer from reliability issues over time. The Oncourt Offcourt Perfect Pitch Rebounder ${ }^{\mathrm{TM}}$ (also rebranded as the EZ shot ${ }^{\mathrm{TM}}$ ) is a stand-alone, mobile backboard with castor wheels. While the frame is non-adjustable, it is made of high-quality tubular steel and appears very sturdy.

Recent developments in the field of tennis backboards continue to evolve and this fact is highlighted by the need for portable backboards in the sporting equipment industry in general. Several attempts have been made to disclose a flat, tennis, practice, backboard that can be hung on a vertical surface (McNamara, 1999; Lombardi, Hult, \& Trowbridge, 1983; Redlich, \& Redlich, 1997; and McTavish, 2010). Yamanashi (2015) showed that a mobile backboard can be stretched between an adjustable frame allowing players to conduct training from a preferable 'hitting-back' position. Researchers observed that an A-frame, setup-type of ball return system disclosed in Gorton's portable rebounding ball game (Gorton, 2007) had an unpredictable rebound trajectory. Similar results were recorded by Schmutte (1992) who revealed that accordion-shaped practice apparatus ball return systems were unreliable. The system directed balls to drop into the bottom net and subsequently limited their ability to rebound to the player. Despite the limitations of these systems, they still tend to represent an improvement in portable backboards. Much of the research up to this point in time does not examine the ability of backboards having the ability to adjust board rebound angle. In fact no research was found examined portable back boards that could be rolled up and installed on a tennis court fence and carried in a single backpack. Research the tennis backboards have been mostly restricted to limited comparisons of non-hanging, non-portable, and stand-alone versions. While some of these research did examine adjustable angles for various returns stand alone backboards, no previous studies were found that investigated the performance of portable backboards that can be unrolled and installed upon a plurality of tennis court fences. The present study seeks to address these gaps by examining the engineering steps taken to engineer, design and test a hanging tennis backboard. The article also reports on some of the challenges encountered during the process of allowing the prototype to perform returns reliably.

\section{Methodology}

A single case study was conducted mainly to examine the engineering steps taken to develop a working prototype of a portable hanging tennis backboard - along with the various challenges encountered during fabrication and field testing. This approach was selected to inform practitioners 
INTERNATIONAL JOURNAL OF ACADEMIC RESEARCH IN BUSINESS AND SOCIAL SCIENCES

Vol. 8, No. 12, Dec, 2018, E-ISSN: 2222-6990 @ 2018 HRMARS

in the area of sport engineering. Multiple challenges we faced during the process of the invention (Yin 2009). Although it is understood that a single case study cannot provide a solution to all such training scenarios, the intent is to at least provide some form of analytical discussion that can be generalized to field (Welsh 2001; Tellis 1997; Hamel et al. 1993).

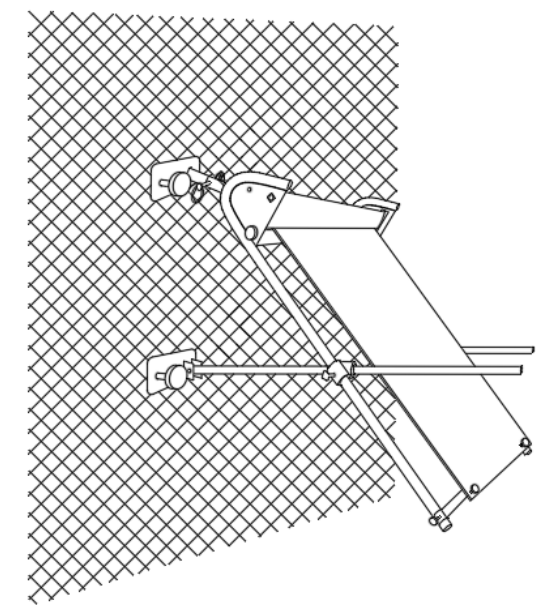

Figure 1. The HTB

A key feature of any ball sport training apparatus is the return mechanism. Such a mechanism has to allow for a wide-range of returns and grant the user a maximum amount of control to tailor such returns to their specific training needs. The HTB seen in Figure 1 was designed for this specific purpose in mind. The first surface a ball comes in contact with in a training apparatus is the backboard. These surfaces are generally made of a flexible fabric such as canvas, vinyl etc. and are the first dampening mechanism within the apparatus. The flexible material absorbs the initial velocity of the ball and a commonality found in most of the backboards examined is the upper rebound curve (see Figure 2.). This curvature in the upper portion of the HTB backboard (a flexible rubber mat) is created by tensioned springs clipped onto the frame creating a damping effect on a tennis ball traveling at high speed. Dapening slows the ball down allowing it to return at very low speed with a steep angle for a low shot return. 


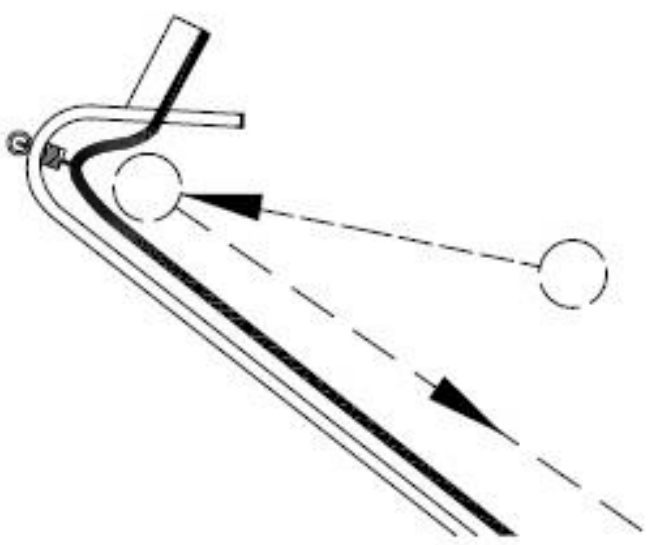

Figure. 2. Upper Curved Rebound

A unique feature of the HTB is the backboard adjustment at the top juncture. When the backboard is released from the retaining springs, it looses its curvature and allows a ball to rebound from a top rail (introduced below) with high-speed and at a low angle for a far shot return - see Figure 3 below.

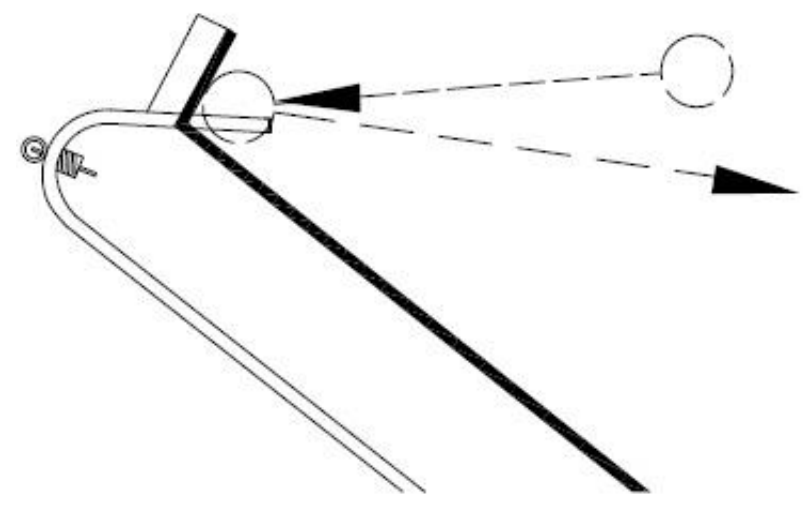

Figure 3. Upper Flat Rebound

Conventional, similar, backboard training models allow for the side rails to be tilted at various angles, thereby allowing an infinite number of return options. These upper backboard shapes and tilt adjustment features were also selected for inclusion into the HTB. However, additional angles for returns are provided by the 'blade.' The blade is at the core of the apparatus and is extremely light weight. In order to allow a user to switch between the upper flat and curved rebound settings mentioned above, a pivoting rebound plate was designed. This plate needed to be narrow enough to allow a ball to pass between it and the backboard and still make contact with the curved surface. $A$ hollow, aluminum, foil-shaped blade was selected and a small rod was inserted into the blade and passed through a pocket in the backboard. The diameter of the rod was larger than a lengtwise slot in the blade and allowed the backboard to be affixed to the blade (see the section view in Figure 4). 


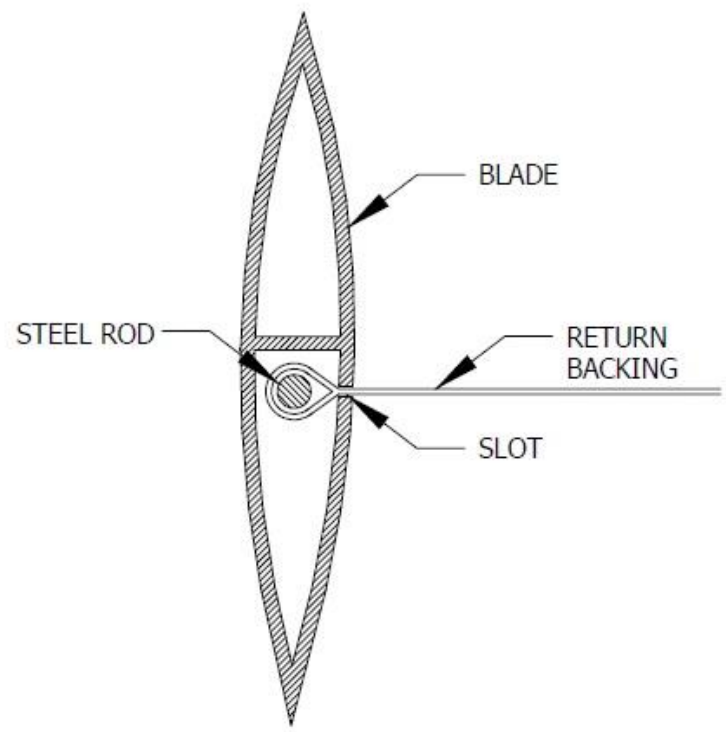

Figure 4. Blade Section View

Each end of the blade was fitted with bolts that allowed it to rotate and lock into two positions - one position allowed for the ball to pass through and generate the low shot return and the other position allowed the blade to make contact with the ball and generate a far shot return. These positions are illustrated in Figure 5.

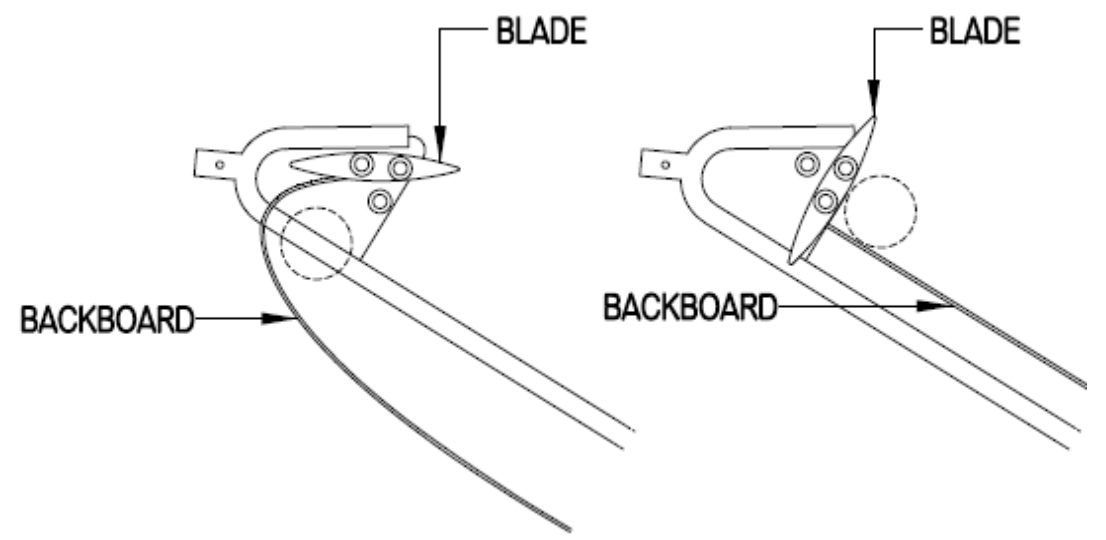

Figure 5. Blade Positions

In order to hang the backboard from a fence, several challenges needed to be addressed when engineering the HTB. The first challenge was to determine how the apparatus would attach to a chain link substrate easily. Because chain link fences consist of long single strands of weaved wire, the connections tend to pivot slightly if grasped at a single point on a wire. For the prototype, four plate claws were developed - two for each top of the rails, and another two for the midsection of each rail. 


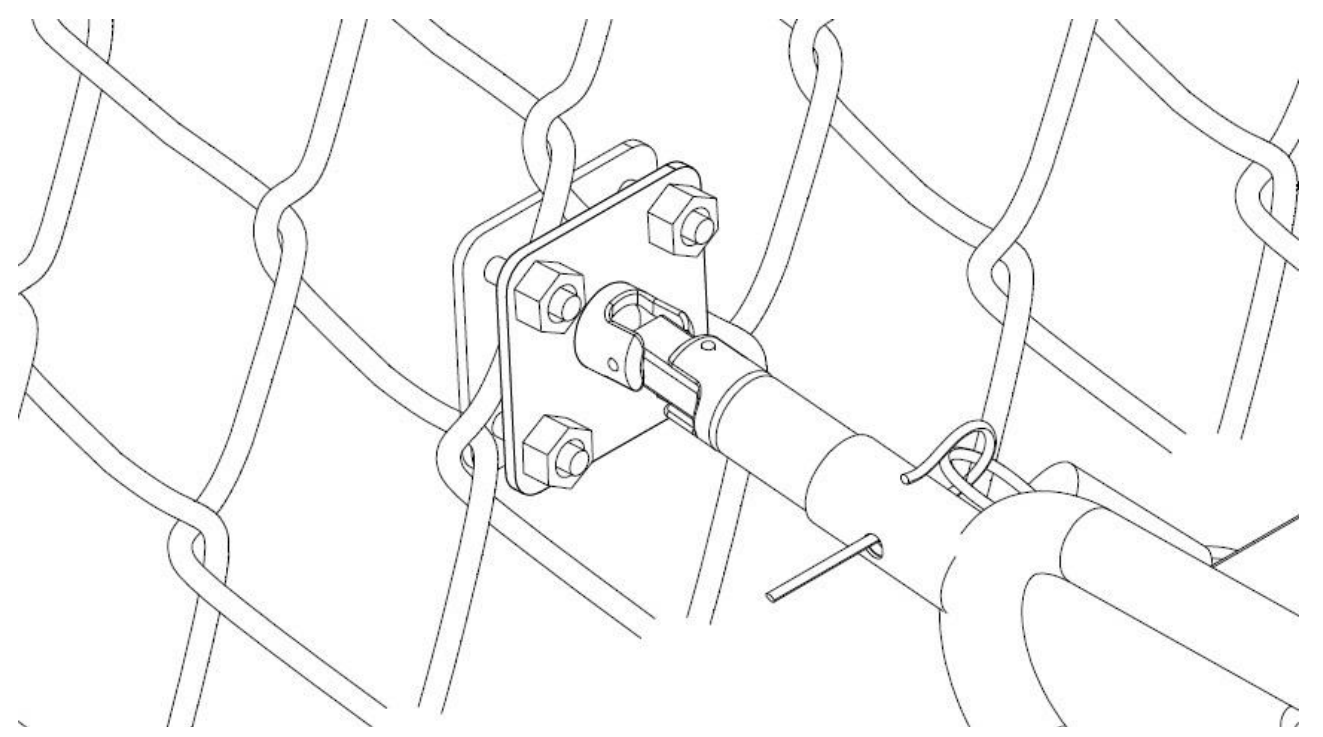

Figure 6. Fence Connections and Linkages

Figure 6 shows the fence connections with two square metal plates connected by four bolts. A universal joint is affixed to the center of the front plate and attaches to the rails by means of a removable clip. The plates clamp on to a series of connections along a fence and allow several of the fence wires to support the backboard at each corner. In order to allow the rails to adjust to different angles for greater return options, a swivel coupling was attached to the rail and down tube. The coupling has two sleeves connected by a pivoting axis and a thumb crimp knob on each sleeve allows the sleeves to be locked at various angles, see Figure 7. Examples of various rail and down tube angles can be seen in Figure 8.

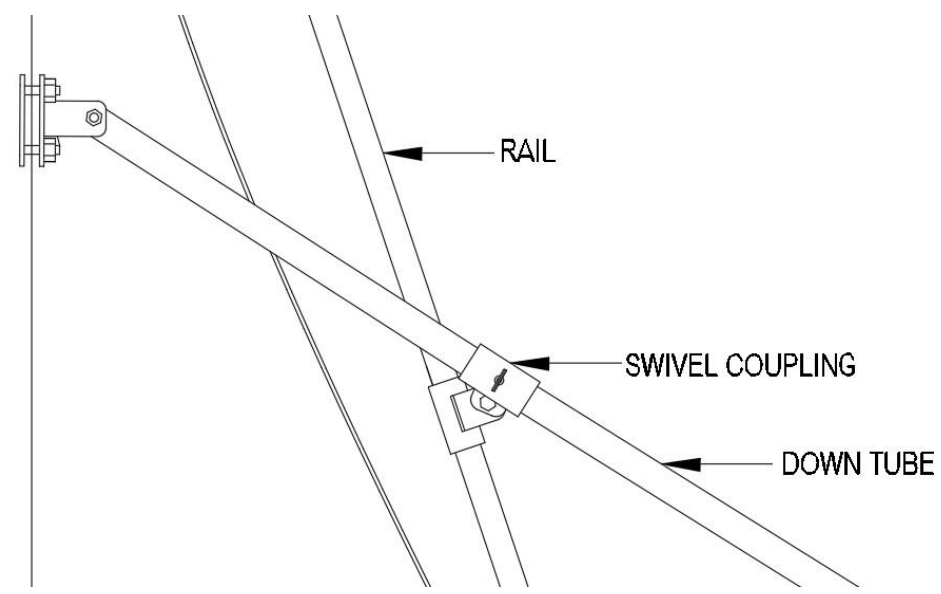

Figure 7. Swivel Coupling. 

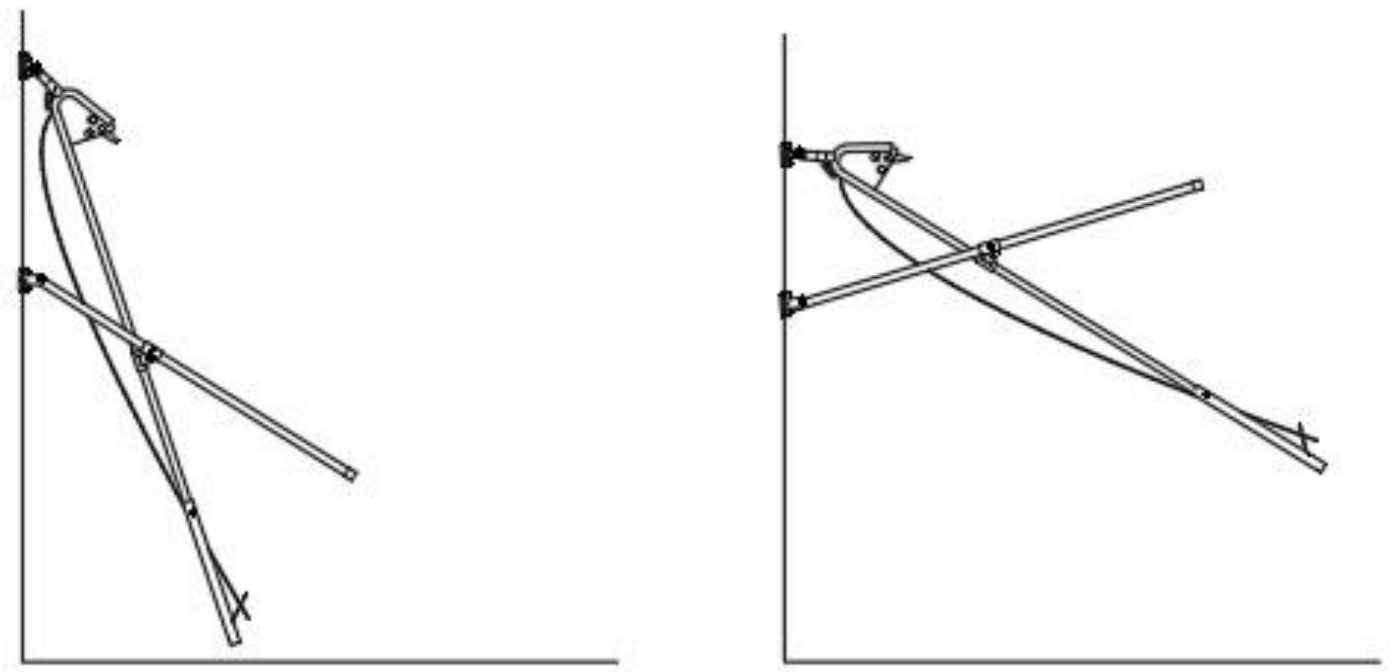

Figure 8. Installation Angles

Similar to other backboards, the bottom rails were attached to sliding tubes with finger knobs that allow the canvas mat backboard to slide up and down on the rails to accommodate the various blade positions.

\section{Discussion}

Once the prototype was completed test trials were conducted. The HTB was setup and tested by a collegiate tennis coach on an actual court fence at Hobart William Smith Colleges (HWS) in Upstate New York, United States in the spring of 2018 (see Figure 9). It took two individuals to attach the rails to each end of the blade. One person held the backboard against the fence while the other person went around behind the fence and attached the bolt plates. Aligning the HTB level on the fence was somewhat challenging as the mesh fence holes were not always parallel to the ground and the connections were not exactly level. However, the visible blade allowed the testers to eventually locate holes that were close to being parallel to hold the HTB level to the court. 


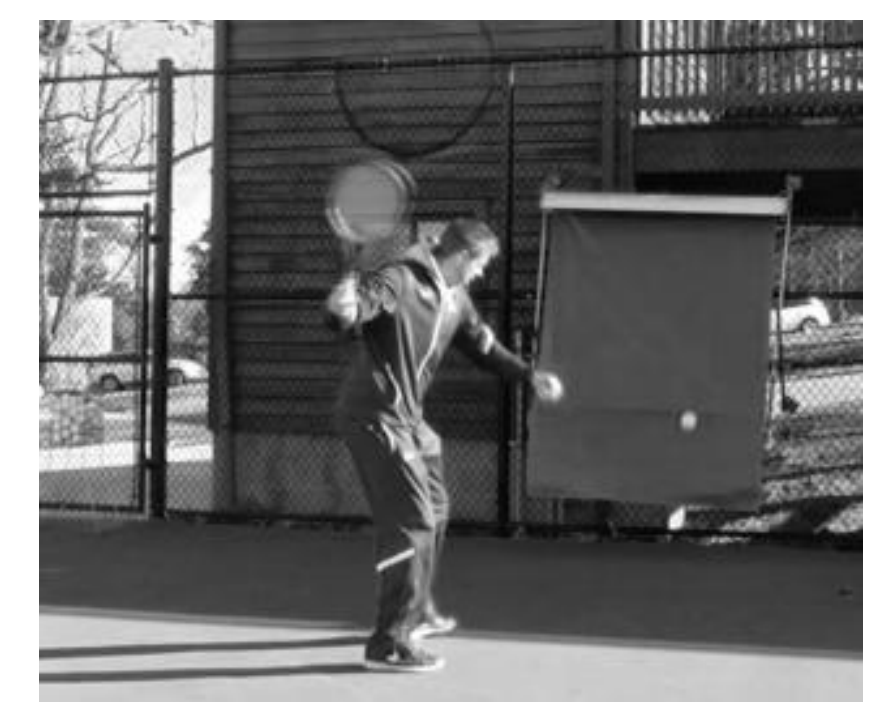

Figure 9. Field Testing (courtesy HWS Colleges)

Fastening the nuts to the bolts was somewhat time consuming and challenging while the blade was held at head hight. At the same time, the blade (being made of thin-walled hollow aluminum) was very light to handle and holding for long periods was not strenuous. The universal joints at the couplings made final leveling adjustments to the rails and down tubes easy. The swivel couplings also allowed final adjustments to the rails simple and the lock knobs held the desired angle securely. At low angles to the fence the rails and down tubes were out of the way; however, for far returns, these angles changed and they extend out toward the player and may become a safety issues for those who happen to walk into the apparatus unintentionally. Overall setup time for the apparatus was under 20 minutes.

Once the angle of the HTP was set, the HWS coach began using the prototype. He positioned himself close to, and directly in front of, the backboard and began hitting hard shots into the apparatus. The backboard returned the ball as expected and fence disturbance was minimal. Testing continued for a half hour as different shots at various angles were conducted and the returns were reported to be quite acceptable. Adjustments of the blade were accomplished by loosening the connection points and allowed for a sharp contrast in return angles. Blade adjustments, in conjunction with backboard angle adjustments allowed were simple to perform and allowed for an infinite number of return angles. It was determined that both slow, near shot returns and quick, far shot returns were accomplished quite easily. The overall structural integrity of the apparatus was sound as minimal movement of the connections and materials was minimal. Breakdown of the prototype was somewhat challenging. Several of the attachment nuts were dropped when attempting to remove the HTB from the fence. Again, two people were needed to remove the device from the fence to avoid damaging or bending tubes or sleeve connections. However, the process was not time consuming and the entire assembly was compacted down for transport in less than 15 minutes. 


\section{Conclusion}

This case study examined the engineering steps taken to develop a working prototype of a HTB along with the various challenges encountered during fabrication and field testing. This study makes an important contribution to the field of sport engineering research and on the production of sports equipment by demonstrating a reliable and functional unique hanging tennis backboard to aid players in practicing tennis without a partner. Findings of this case study were generally considered successful. The HTB performed as was intended - both slow, near shot returns and quick, far shot returns were accomplished. The rotating blade allows for both close and long shot returns and the fence attachment mechanisms held up to fast ball loads. At the same time, installing the fence connections was somewhat challenging and new. Large knobs are now under consideration to replace the bolt sets and improve setup and adjustment times. The universal linkages were considered to be very positive attributes and allowed final adjustments to be performed easily. Likewise, the swivel couplings also had positive outcomes as they allowed for a single user to adjust the angles of the rails and down tubes. Finally, the lightweight blade was also considered a success in fact it's sleek look may even contribute to marketing appeal. While additional, long-term testing is needed to determine the extended reliability of the HTB, results of this case study suggest it has the potential to become a successful product in the tennis equipment market.

\section{Acknowledgements}

This study was part of research funded by the Sultan Idris Education University (scheme of prototype development grant 2016-0208-106-51). Further acknowledgement is given to the Faculty of Sport Science and Coaching, Sultan Idris Education University and HWS colleges for the help and support in completion of this project.

\section{References}

Annapragada, S. K. (2016). U.S. Patent No. 9,302,166. Washington, DC: U.S. Patent and Trademark Office.

Chang, M., \& Moore, H. (2005). U.S. Patent Application No. 10/647,808.

Gorton, N. C. (2007). U.S. Patent No. 7,249,767. Washington, DC: U.S. Patent and Trademark Office.

Hamel, J., Dufour, S., \& Fortin, D. (1993). Case study methods (Vol. 32). Sage Publications, Newbury Park.

Hutchins, A. (2015). U.S. Patent Application No. 14/693,997.

Lombardi, J. P., Hult, T. M., \& Trowbridge Jr, R. H. (1983). U.S. Patent No. 4,373,720. Washington, DC: U.S. Patent and Trademark Office. 
INTERNATIONAL JOURNAL OF ACADEMIC RESEARCH IN BUSINESS AND SOCIAL SCIENCES

Vol. 8, No. 12, Dec, 2018, E-ISSN: $2222-6990$ C 2018 HRMARS

McNamara, P. E. (1999). U.S. Patent No. 5,993,334. Washington, DC: U.S. Patent and Trademark Office.

McTavish, H. (2010). U.S. Patent No. 7,677,993. Washington, DC: U.S. Patent and Trademark Office.

Redlich, G. R., \& Redlich, K. J. (1997). U.S. Patent No. 5,664,784. Washington, DC: U.S. Patent and Trademark Office.

Schmutte, C. T. (1992). U.S. Patent No. 5,116,056. Washington, DC: U.S. Patent and Trademark Office.

Tellis, W. M. (1997). Application of a case study methodology. The qualitative report, 3(3), 1-19.

Welsh, I., \& Lyons, C. M. (2001). Evidence-based care and the case for intuition and tacit knowledge in clinical assessment and decision making in mental health nursing practice: an empirical contribution to the debate. Journal of Psychiatric and Mental Health Nursing, 8(4), 299-305.

Yamanashi, T. (2015). U.S. Patent No. 9,155,952. Washington, DC: U.S. Patent and Trademark Office.

Yin, R. K. (2009). Case study research: Design and methods (applied social research methods). London and Singapore: Sage. 